\title{
In vitro Antioxidant Activities of Sodium Zinc and Sodium Iron Chlorophyllins from Pine Needles
}

\author{
Ruzhen Zhan ${ }^{1,2}$, Jian Wu ${ }^{1,2}$ and Jie Ouyang ${ }^{1,2 *}$ \\ ${ }^{1}$ Department of Food Science and Engineering, College of Biological Sciences and Technology, \\ Beijing Forestry University, Beijing 100083, PR China \\ ${ }^{2}$ Beijing Key Laboratory of Forest Food Processing and Safety, Beijing Forestry University, \\ Beijing 100083, PR China
}

Received: December 18, 2013

Accepted: September 23, 2014

\begin{abstract}
Summary
Chlorophyll was extracted from pine needles, and then sodium zinc chlorophyllin (SZC) and sodium iron chlorophyllin (SIC) were synthesised by saponification, purification and substitution reaction, using sodium copper chlorophyllin (SCC) as a control. Their crystalline structures were verified by atomic absorbance spectroscopy, UV-VIS spectroscopy and HPLC. Moreover, their antioxidant activities were evaluated and compared with that of ascorbic acid through four biochemical assays: DPPH (2,2-diphenyl-1-picrylhydrazyl) radical scavenging activity, reducing power, inhibition of $\beta$-carotene bleaching and $\mathrm{O}_{2}^{-}$scavenging activity. SZC had better antioxidant properties at a lower dosage than SIC and SCC in all assays. In the $\beta$-carotene bleaching assay, $\mathrm{EC}_{50}$ of SZC, SIC and SCC was $0.04,0.38$ and $0.90 \mathrm{mg} / \mathrm{mL}$, respectively, much lower than that of ascorbic acid $(4.0 \mathrm{mg} / \mathrm{mL})$. SZC showed a better result $(\mathrm{p}<0.05)$ than ascorbic acid in the $\mathrm{O}_{2}^{-}$scavenging activity assay. The results obtained from reducing power determination were also excellent: the absorbance values were all about 1.0 at $0.5 \mathrm{mg} / \mathrm{mL}$, about half of that of ascorbic acid. In the investigation of DPPH radical scavenging activity, all chlorophyllins had lower activities than ascorbic acid. These results demonstrated the potential bioactivities of chlorophyll derivatives and supported their possible role in human health protection and disease prevention.
\end{abstract}

Key words: sodium zinc chlorophyllin, sodium iron chlorophyllin, sodium copper chlorophyllin, antioxidant activity, pine needles

\section{Introduction}

Free radicals, as a product of normal metabolism, cause molecular transformations and gene mutations in many types of organisms. In healthy individuals, free radical production is continuously balanced by natural antioxidant defence systems (1). Several redox-active metal-containing compounds have been investigated as potent antioxidants based on their core transition metal mimicking the active site of superoxide dismutase (SOD) and catalase $(2,3)$. Much attention has lately been paid to metalloporphyrins as a novel class of catalytic antioxidants that scav- enge a broad range of reactive oxygen species (ROS), such as superoxide, hydrogen peroxide $\left(\mathrm{H}_{2} \mathrm{O}_{2}\right)$, peroxynitrite $\left(\mathrm{ONOO}^{-}\right)$and lipid peroxyl radicals $(4,5)$. Accumulating evidence has demonstrated that metalloporphyrins have been very effective in mitigating the toxic effects of reactive oxygen or nitrogen species, indicating that they are promising antioxidants for clinical applications (6-9).

Chlorophyll and copper complex of chlorophyll have been permitted to be used as food colours in the EU with code numbers E140 and E141, respectively. Furthermore, chlorophyll as an effective antioxidant compound is attracting more and more attention. A line of studies has revealed 
that chlorophyll not only scavenges hydroxyl radical and singlet oxygen $\left({ }^{1} \mathrm{O}_{2}\right)$, but also prevents lipid peroxidation from oxidative damage (10-13). Moreover, metal chelation of chlorophyll is known to strengthen the antioxidant activity of tetrapyrroles (14). These findings raised the possibility that metal-containing chlorophyll derivatives may be potent antioxidant compounds. Copper chlorophyllin had a higher antioxidant activity than natural chlorophylls, showing the importance of the nature of the chelated metal in the porphyrin ring (15).

Sodium copper chlorophyllin (SCC), now commercially available, contains a copper atom in the centre of the ring of chlorophyllin (Fig. 1). Sodium zinc chlorophyllin (SZC) and sodium iron chlorophyllin (SIC) can also be formed with metal ions in the porphyrins. In the present work, chlorophyll was extracted from pine needles, then SCC, SZC and SIC were synthesised by saponification, substitution reaction and purification. Their antioxidant activities were evaluated and compared with ascorbic acid through four biochemical assays: DPPH (2,2-diphenyl-1picrylhydrazyl) radical scavenging activity, reducing power, inhibition of $\beta$-carotene bleaching and $\mathrm{O}_{2}^{-}$scavenging activity.

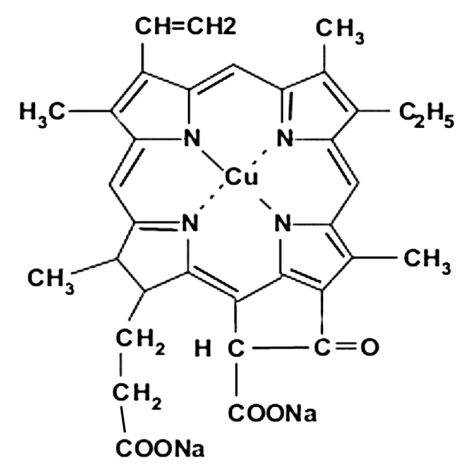

Fig. 1. Structure of sodium copper chlorophyllin. Zinc or iron atom may also chelate in the centre of the ring to form sodium zinc chlorophyllin or sodium iron chlorophyllin

\section{Material and Methods}

\section{Material and chemicals}

Pine needles were collected from the suburb of Beijing, PR China. DPPH (2,2-diphenyl-1-picrylhydrazyl) was obtained from Alfa Aesar (Ward Hill, MA, USA), while L-ascorbic acid, $\beta$-carotene, potassium ferricyanide, riboflavin and all other reagents were of analytical grade and purchased from Sinopharm Chemical Reagent Co., Ltd., Beijing, PR China.

\section{Synthesis of sodium copper, sodium zinc and sodium iron chlorophyllins}

The extraction of chlorophyll from pine needles, saponification, purification, synthesis and crystallization of SCC, SZC and SIC were carried out according to previously described methods (16-18). The crystals of SCC, SZC and SIC were of blue-black, dark green and black colours, respectively, all with metallic lustre.

\section{UV-VIS spectroscopy of SCC, SZC and SIC}

SCC, SZC and SIC were dissolved in distilled water to prepare solutions of $10 \mathrm{mg} / \mathrm{mL}$. The UV-VIS absorption spectra at a wavelength between 200 and $700 \mathrm{~nm}$ were scanned with Shimadzu UV 2550 spectrophotometer (Kyoto, Japan).

\section{Determination of copper, zinc and iron content in SCC, SZC and SIC}

The content of copper, zinc and iron in SCC, SZC and SIC, respectively, was assayed by atomic absorption spectrometer (iCE3500; Thermo Scientific, Waltham, MA, USA) with the methods described in Chinese National Standards GB/T 5009.13-2003, GB/T 5009.90-2003 and GB/T 5009.14-2003, respectively.

\section{HPLC analysis of SCC, SZC and SIC}

The purity of SCC, SZC and SIC was analysed by HPLC on Shimadzu LC-20AT system with an SPD-M20A diode array detector. Analysis was performed on a reversed phase Inertsil ${ }^{\circledR}$ ODS-2 column $(4.6 \mathrm{~mm} \times 250 \mathrm{~mm}, 5$ $\mu \mathrm{m}$; Shimadzu). The mobile phase was methanol/water (80:20, by volume) containing $0.1 \%$ (by volume) of acetic acid. The detection wavelength was $405 \mathrm{~nm}$, and the flow rate was $1.0 \mathrm{~mL} / \mathrm{min}$.

\section{DPPH radical scavenging activity}

DPPH radical scavenging activity of chlorophyll derivatives was measured using the method described by Duan et al. (19) and compared with those of ascorbic acid. A volume of $2 \mathrm{~mL}$ of diluted sample was mixed with $2 \mathrm{~mL}$ of $5 \cdot 10^{-5} \mathrm{M}$ DPPH in ethanol and incubated at $37^{\circ} \mathrm{C}$ for 30 min in the dark (until stable absorbance values were obtained). The absorbance of the sample after incubation was measured at $517 \mathrm{~nm}$, and the DPPH radical scavenging activity was calculated as:

$$
\text { Radical scavenging activity }=\left(1-A_{\mathrm{DPPH}} / A_{\mathrm{S}}\right) \cdot 100
$$

where $A_{\mathrm{DPPH}}$ is the absorbance of the DPPH solution, and $A_{\mathrm{S}}$ is the absorbance of the solution when sample solution was added. $\mathrm{EC}_{50}$ of the DPPH radical scavenging activity was calculated from the graph of the percentage of radical scavenging activity against sample concentration.

\section{Reducing power}

The ferric reducing antioxidant power (FRAP) assay was determined according to the modified method of Oyaizu (20). Ascorbic acid, SCC, SZC and SIC were dissolved in ethanol to the concentrations of $0.05,0.1,0.2,0.5$ and $1 \mathrm{mg} / \mathrm{mL}$, respectively. Aliquots $(0.5 \mathrm{~mL})$ of 0 (control, i.e. $0.5 \mathrm{~mL}$ of ethanol instead of sample solution) or $1.5 \mathrm{~mL}$ of sample solutions were mixed with $0.2 \mathrm{M}$ sodium phosphate buffer ( $\mathrm{pH}=6.6,2.5 \mathrm{~mL})$ and $1 \%$ (by mass per volume) potassium ferricyanide $(2.5 \mathrm{~mL})$. The mixture was then incubated at $50{ }^{\circ} \mathrm{C}$ for $20 \mathrm{~min}$. After the addition of 10 $\%$ (by mass per volume) trichloroacetic acid $(2.5 \mathrm{~mL})$ into each sample, the mixture was centrifuged at $650 \times g$ for 10 $\mathrm{min}$. An aliquot of $5 \mathrm{~mL}$ of the upper layer was mixed with distilled water $(5 \mathrm{~mL})$ and $0.1 \%$ (by mass per volume) ferric chloride $(1 \mathrm{~mL})$. The absorbance was measured at 700 $\mathrm{nm}$ by UV 2550 spectrophotometer (Shimadzu). Higher absorbance indicated higher reducing power. 


\section{Inhibition of $\beta$-carotene bleaching}

The antioxidant activities of SCC, SZC and SIC were evaluated by the $\beta$-carotene linoleate model system. A solution of $\beta$-carotene was prepared by dissolving $2 \mathrm{mg}$ of $\beta$-carotene in $50 \mathrm{~mL}$ of chloroform. A volume of $50 \mu \mathrm{L}$ of linoleic acid, $0.37 \mathrm{~mL}$ of Tween 80 emulsifier and $\beta$-carotene solution were pipetted into a $500-\mathrm{mL}$ round-bottomed flask. After the chloroform was removed at $40{ }^{\circ} \mathrm{C}$ under vacuum, $400 \mathrm{~mL}$ of distilled water were added to the flask with vigorous shaking. Aliquots $(4.5 \mathrm{~mL})$ of this emulsion were transferred into different test tubes containing $0.5 \mathrm{~mL}$ of different concentrations of the samples. The tubes were shaken and incubated at $50^{\circ} \mathrm{C}$ in a water bath. As soon as the emulsion was added to each tube, the zero time absorbance was measured at $470 \mathrm{~nm}$ using a spectrophotometer. Absorbance readings were then recorded at 20-minute intervals until the control sample had changed colour. A blank, devoid of $\beta$-carotene, was prepared for background subtraction. Lipid peroxidation inhibition was calculated using the following equation (21):

Lipid peroxidation inhibition $=(\beta$-carotene content after $2 \mathrm{~h}$ of assay/initial $\beta$-carotene content) 100 /2/

The extract concentration providing $50 \%$ antioxidant activity $\left(\mathrm{EC}_{50}\right)$ was calculated from the graph of antioxidant activity percentage against extract concentration. Ascorbic acid was used as a standard.

\section{$\mathrm{O}_{2}^{-}$scavenging activity}

Superoxide anion radicals $\left(\mathrm{O}_{2}^{-}\right)$were generated photochemically in a medium containing $50 \mathrm{~mL}$ of potassium phosphate buffer $(\mathrm{pH}=7.8), 7.7 \cdot 10^{-9} \mathrm{M}$ riboflavin, $1.3 \cdot 10^{-2} \mathrm{M}$ methionine, $6.3 \cdot 10^{-5} \mathrm{M}$ nitro blue tetrazolium (NBT), and $10^{-4} \mathrm{M}$ EDTA. The reduction of NBT by $\mathrm{O}_{2}^{-}$was measured in the presence of increasing concentrations of the tested chlorophyllins and ascorbic acid after a 15-minute exposure of the samples to light followed by a spectrophotometric measurement at $560 \mathrm{~nm}$ according to the method of Beauchamp and Fridovich (22).

\section{Statistical analysis}

All experiments were carried out in triplicate and the results are expressed as mean values. Means were compared using Tukey's honestly significant difference (HSD) multiple comparison test using SPSS software v. 17.0 (IBM Corporation, Armonk, NY, USA).

\section{Results and Discussion}

\section{Synthesis and determination of SCC, SZC and SIC}

SCC, SZC and SIC were crystallized from pine needles using the method described above, and $1.99 \mathrm{~g}$ of SCC, $1.74 \mathrm{~g}$ of SZC and $2.24 \mathrm{~g}$ of SIC crystals were obtained from $100 \mathrm{~g}$ of pine needle powder. The mass fractions of copper, zinc and iron were 9.00, 9.14 and $8.00 \%$ in SCC, SZC and SIC, which were close to the theoretical values of $8.70,8.93$ and $7.73 \%$, respectively. All three chlorophyll derivatives were easily soluble in water, and the colour of SCC, SZC and SIC solutions at the concentration of $10 \mathrm{mg} / \mathrm{mL}$ was dark green, emerald, and dark brown, respectively.
From the UV-VIS absorption spectra of SCC, SZC and SIC, the absorption peaks were 402,415 and $405 \mathrm{~nm}$, respectively, similar to the results of other researchers, where the peaks of SCC were 404 and $627 \mathrm{~nm}$ (23), the peak of SZC was $410 \mathrm{~nm}$ and that of SIC was $405 \mathrm{~nm}$. The results of HPLC analysis revealed that the purity of SCC, SZC and SIC was $96.1,96.3$ and $96.0 \%$ (Fig. 2), respectively.
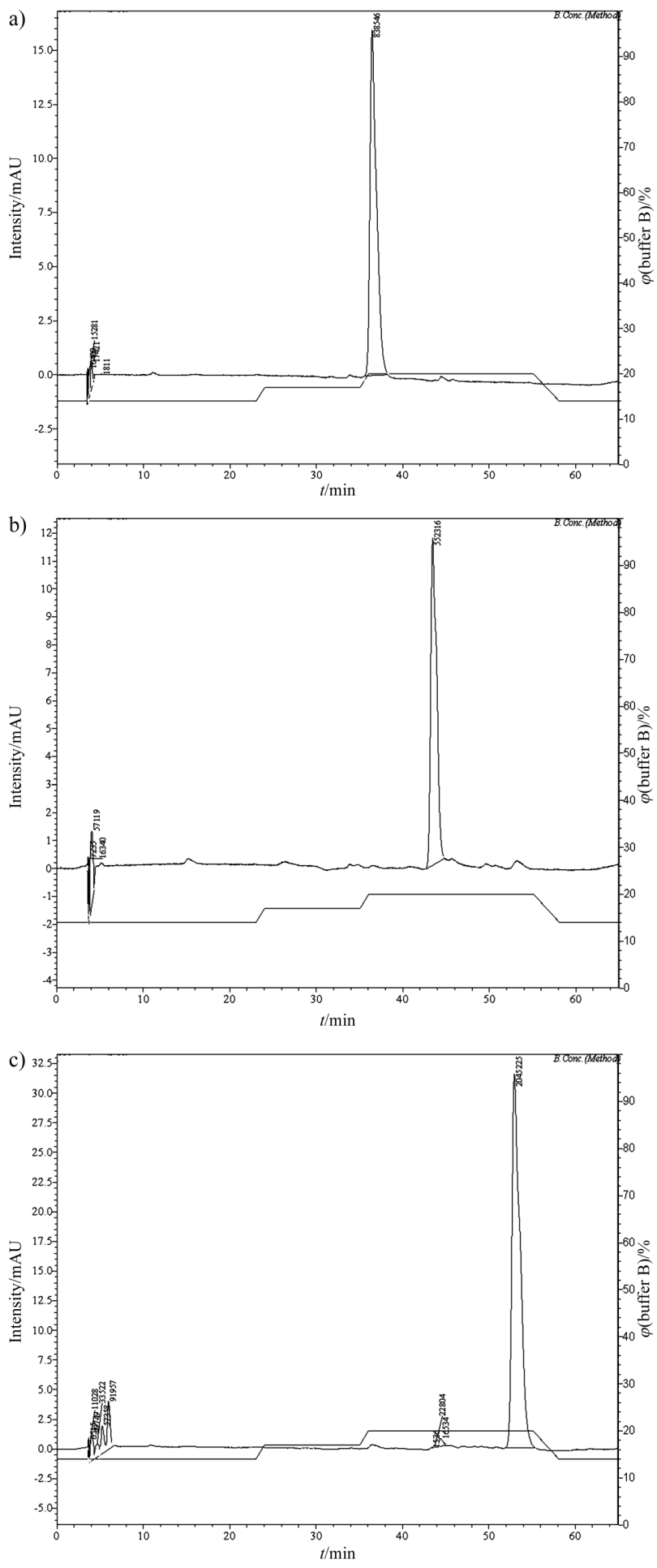

Fig. 2. HPLC chromatograms of: a) sodium copper chlorophyllin, b) sodium zinc chlorophyllin, and c) sodium iron chlorophyllin 


\section{Antioxidant activities of SCC, SZC and SIC in vitro}

Figs. 3-5 show the antioxidant activity of SCC, SZC and SIC examined as a function of their concentrations. Several biochemical assays were used to screen the antioxidant properties: scavenging activity on DPPH radicals (measuring the decrease in DPPH radical absorption after exposure to radical scavengers), reducing power (measuring the conversion of a ferricyanide complex to the ferrous form), inhibition of $\beta$-carotene bleaching (by neutralizing the linoleate-free radical and other free radicals formed in the system which attack the highly unsaturated $\beta$-carotene models), and $\mathrm{O}_{2}^{-}$scavenging activity (evaluating the electronic donation of the samples to NBT which generates superoxide anions under aerobic conditions).

Results in Fig. 3 reveal that antioxidant activity increased with the increase of the concentration of chlorophyllins. It can be concluded that the scavenging effects of ascorbic acid, SCC, SZC and SIC on DPPH radicals increased with the increase of their concentrations. The DPPH radical scavenging activities of SCC, SZC and SIC (98.8, 69.9 and $91.4 \%$, respectively, at $10 \mathrm{mg} / \mathrm{mL}$ ) were significantly $(\mathrm{p}<0.01)$ lower than that of ascorbic acid $(98.5 \%$ at $\left.2.5 \cdot 10^{-2} \mathrm{mg} / \mathrm{mL}\right)$. At $5 \mathrm{mg} / \mathrm{mL}$, the activity of SCC $(93.5$ $\%)$ was much greater compared with other two chlorophyllins (37.9\% of SZC and $26.5 \%$ of SIC). Half of the maximum effective concentration $\left(\mathrm{EC}_{50}\right)$ of ascorbic acid was $9 \cdot 10^{-3} \mathrm{mg} / \mathrm{mL}, \mathrm{EC}_{50}$ of SCC was $2.6 \mathrm{mg} / \mathrm{mL}$, significantly $(p<0.01)$ lower than those of SZC and SIC (both were approx. $7 \mathrm{mg} / \mathrm{mL}$ ).

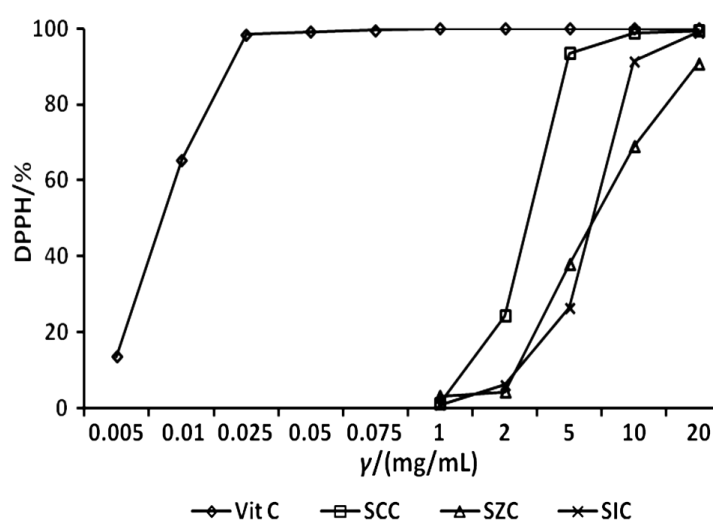

Fig. 3. Relationship between DPPH radical scavenging activity and the concentrations of ascorbic acid (Vit C), sodium copper chlorophyllin (SCC), sodium zinc chlorophyllin (SZC), and sodium iron chlorophyllin (SIC)

The reducing power also increased with the increase of chlorophyllin concentration, and the values obtained for SCC, SZC and SIC were all excellent, although they were about half of that of ascorbic acid (Fig. 4). At $0.5 \mathrm{mg} /$ $\mathrm{mL}$, the absorbance values of SCC and SZC were above 1.0 , higher than that of SIC $(p<0.01)$. It has been reported that the reducing properties are generally associated with the presence of reductones, which have been shown to exert antioxidant action by donating a hydrogen atom and breaking the free radical chain (24). However, the mechanism of antioxidant activity displayed by the natural chlorophyll derivatives does not seem to be based on the ability to donate hydrogen, but maybe on the protection of

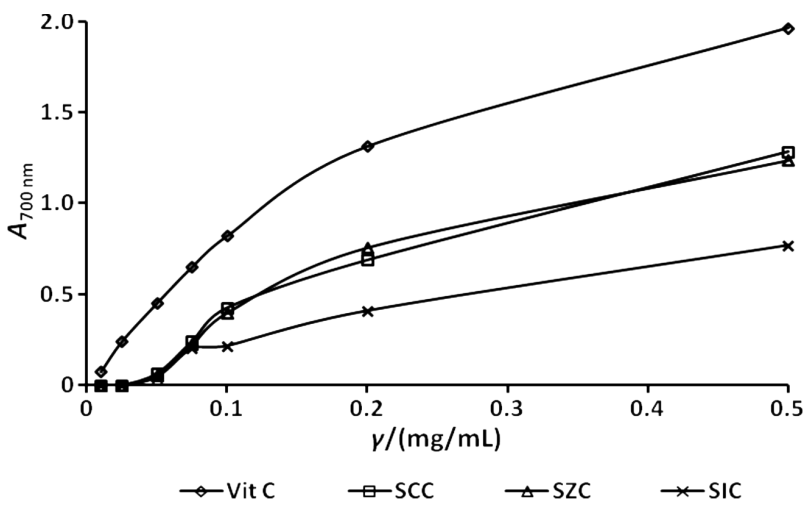

Fig. 4. Relationship between the reducing power (measured as $\left.A_{700 \mathrm{~nm}}\right)$ and the concentrations of ascorbic acid (Vit C), sodium copper chlorophyllin (SCC), sodium zinc chlorophyllin (SZC), and sodium iron chlorophyllin (SIC)

linoleic acid against oxidation and/or preventing decomposition of hydroperoxides (15). Hence, SCC and SZC are more likely to have this ability.

The bleaching inhibition, measured by the peroxidation of $\beta$-carotene, is presented in Fig. 5. The linoleic acid free radicals attack the highly unsaturated $\beta$-carotene. The presence of different antioxidants can hinder the extent of $\beta$-carotene bleaching by neutralizing the linoleate-free radical and other free radicals formed in the system (25). Accordingly, the absorbance decreased rapidly in the samples without an antioxidant, whereas in the presence of an antioxidant, samples retained their colour, and the absorbance lasted longer. Bleaching inhibition in the presence of SCC, SZC and SIC, as well as ascorbic acid, increased with the increase of their concentration and was extremely good. The values at $5 \mathrm{mg} / \mathrm{mL}$ for each one of the samples were all above $50 \%$ (ascorbic acid 52.8, SCC 74.4, SZC 82.0 and SIC $90.2 \%$ ). It is possible that the antioxidant effect in these samples can reduce the extent of $\beta$-carotene destruction by neutralizing the linoleate-free radical and other free radicals formed in the system. The $\mathrm{EC}_{50}$ concentrations of ascorbic acid, SZC, SIC and SCC were $4.0,0.04,0.38$ and $0.90 \mathrm{mg} / \mathrm{mL}$, respectively. Obviously, the inhibition of $\beta$-carotene bleaching by SCC, SZC and SIC was more effective $(p<0.01)$ than by ascorbic acid, and the antioxidant effect of SZC was especially good.

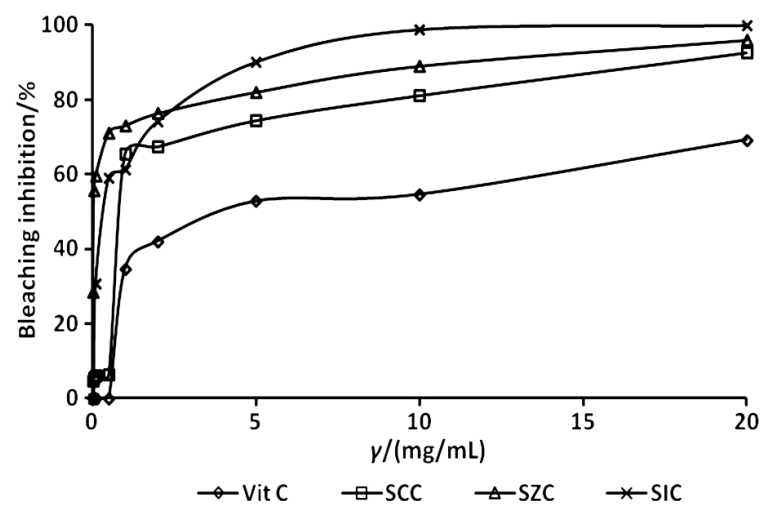

Fig. 5. Relationship between the inhibition of $\beta$-carotene bleaching and the concentrations of ascorbic acid (Vit C), sodium copper chlorophyllin (SCC), sodium zinc chlorophyllin (SZC), and sodium iron chlorophyllin (SIC) 
The $\mathrm{O}_{2}^{-}$scavenging activity also increased with the increase of chlorophyll derivative concentrations, and the absorbance values were all above 0.5 for all samples at the concentration of $1 \mathrm{mg} / \mathrm{mL}$ (Fig. 6). SZC gave a better result

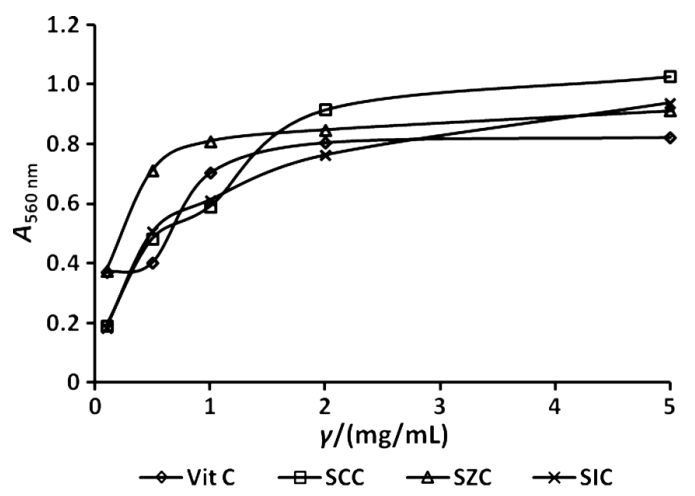

Fig. 6. Relationship between the $\mathrm{O}_{2}^{-}$scavenging activity (measured as $A_{560 \mathrm{~nm}}$ ) and the concentrations of ascorbic acid (Vit C), sodium copper chlorophyllin (SCC), sodium zinc chlorophyllin (SZC), and sodium iron chlorophyllin (SIC)

compared with ascorbic acid $(p<0.05)$, SCC $(p<0.01)$ and SIC $(\mathrm{p}<0.01)$. The test implements two principal reactions (26):

$$
\begin{gathered}
2 \mathrm{NBTH}^{\cdot} \rightarrow \mathrm{NBT}+\mathrm{NBTH}_{2} \text { (formazan) } \\
\mathrm{NBTH}^{\cdot}+\mathrm{O}_{2} \leftrightarrow \mathrm{NBT}^{+}+\mathrm{O}_{2}{ }^{-}+\mathrm{H}^{\cdot}
\end{gathered}
$$

When the riboflavin is photochemically activated, it reacts with NBT to give NBTH, which leads to formazan according to Eq. 3. In the presence of oxygen, concentrations of radical species are controlled by the quasi equilibrium (Eq. 4). Therefore, superoxide anions appear indirectly when the test is performed under aerobic conditions. In the presence of an antioxidant that can donate an electron to NBT, the purple colour typical of the formazan decays.

A research group in Japan first suggested a prooxidant activity of chlorophylls under light, which could be understood as a transfer of the energy of singlet-excited chlorophyll to oxygen that would form reactive oxygen species $(27,28)$. However, the same authors also reported that chlorophylls and pheophytins provide protection by preventing autoxidation of edible vegetable oils stored in the dark and suggested a hydrogen-donating mechanism which breaks the radical chain reactions. In addition, they stated that the intact chemical structure of porphyrin seems to be essential for antioxidant activity.

SCC is derived from a crude natural chlorophyll extract by reaction with methanolic sodium hydroxide, followed by a replacement of the central magnesium atom with copper (29). Antioxidant activity of SCC as a chlorophyllin derivative had also been proposed because the presence of a transition metal in the tetrapyrrole macrocycle had been postulated to alter potential antimutagenic activity (30). Pheophorbide b and SCC showed effective protection against linoleic acid oxidation in $\beta$-carotene bleaching test: only about $20 \%$ of $\beta$-carotene was decolourised when both concentrations were $226.8 \mu \mathrm{M}$ (50 ppm of BHT equivalent), while $10 \%$ was decolourised by BHT at 50 ppm; SCC, chlorophylls and BHT at the concentration of $1 \mathrm{mM}$ (200 ppm of BHT equivalent) scavenged around 39, 12 and $43 \%$ of DPPH, respectively (15). The concentration of chlorophylls and their derivatives in the above research was at the same level as the present study. The structures of SZC and SIC are both similar to SCC, and also showed excellent antioxidant activities.

\section{Conclusions}

The results show that the antioxidant activities of SCC, SZC and SIC had a dose-dependent response. In the experiment of inhibition of $\beta$-carotene bleaching, the effect of SCC, SZC and SIC was even better than of ascorbic acid, especially of SZC. However, in the DPPH radical scavenging activity assay, the effective dosage of ascorbic acid was more than ten times lower than that of SCC, SZC and SIC at the same scavenging rate. These results further demonstrate the potential bioactivity of chlorophyll derivatives and support a possible role of these salts in human health protection and disease prevention.

\section{Acknowledgements}

The authors thank for the support of 'The 44th Scientific Research Foundation for the Returned Overseas' from the Ministry of Education of the People's Republic of China.

\section{References}

1. J.M. Gutteridge, Free radicals in disease processes: A compilation of cause and consequence, Free Radic. Res. Commun. 19 (1993) 141-158. http://dx.doi.org/10.3109/10715769309111598

2. B.J. Day, Catalytic antioxidants: A radical approach to new therapeutics, Drug Discov. Today, 9 (2004) 557-566. http://dx.doi.org/10.1016/S1359-6446(04)03139-3

3. G. DeFreitas-Silva, J.S, Reboucas, I. Spasojević, L. Benov, Y.M. Idemori, I. Batinić-Haberle, SOD-like activity of Mn(II) beta-octabromo-meso-tetrakis (N-methylpyridinium-3-yl) porphyrin equals that of the enzyme itself, Arch. Biochem. Biophys. 477 (2008) 105-112. http://dx.doi.org/10.1016/j.abb.2008.04.032

4. S.W. Rabkin, S.S. Klassen, Metalloporphyrins as a therapeutic drug class against peroxynitrite in cardiovascular diseases involving ischemic reperfusion injury, Eur. J. Pharmacol. 586 (2008) 1-8. http://dx.doi.org/10.1016/j.ejphar.2008.02.078

5. M. Patel, B.J. Day, Metalloporphyrin class of therapeutic catalytic antioxidants, Trends Pharmacol. Sci. 20 (1999) 359-364 http://dx.doi.org/10.1016/S0165-6147(99)01336-X

6. H.L. Liang, G. Hilton, J. Mortensen, K. Regner, C.P. Johnson, V. Nilakantan, MnTMPyP, a cell-permeant SOD mimetic, reduces oxidative stress and apoptosis following renal ischemia-reperfusion, Am. J. Physiol. Renal Physiol. 296 (2009) 266-276. http://dx.doi.org/10.1152/ajprenal.90533.2008

7. I. Batinić-Haberle, S. Cuzzocrea, J.S. Reboucas, G. Ferrer-Sueta, E. Mazzon, R. Di Paola et al., Pure MnTBAP selectively scavenges peroxynitrite over superoxide: Comparison of pure and commercial MnTBAP samples to MnTE-2-PyP in two models of oxidative stress injury, an SOD-specific Escherichia coli model and carrageenan-induced pleurisy, Free 
Radic. Biol. Med. 46 (2009) 192-201.

http://dx.doi.org/10.1016/j.freeradbiomed.2008.09.042

8. Z.N. Rabbani, I. Spasojevic, X. Zhang, B.J. Moeller, S. Haberle, J. Vasquez-Vivar et al., Antiangiogenic action of redoxmodulating $\mathrm{Mn}(\mathrm{III})$ mesotetrakis (N-ethylpyridinium-2-yl) porphyrin, MnTE-2-PyP(5), via suppression of oxidative stress in a mouse model of breast tumor, Free Radic. Biol. Med. 47 (2009) 992-1004. http://dx.doi.org/10.1016/j.freeradbiomed.2009.07.001

9. H. Sheng, W. Yang, S. Fukuda, H.M. Tse, W. Paschen, K. Johnson et al., Long-term neuroprotection from a potent redox-modulating metalloporphyrin in the rat, Free Radic. Biol. Med. 47 (2009) 917-923.

http://dx.doi.org/10.1016/j.freeradbiomed.2009.05.039

10. S.S. Kumar, T.P.A. Devasagayam, B. Bhushan, N.C. Verma, Scavenging of reactive oxygen species by chlorophyllin: An ESR study, Free Radic. Res. 35 (2001) 563-574. http://dx.doi.org/10.1080/10715760100301571

11. S.S. Kumar, B. Shankar, K.B. Sainis, Effect of chlorophyllin against oxidative stress in splenic lymphocytes in vitro and in vivo, Biochim. Biophys. Acta, 1672 (2004) 100-111. http://dx.doi.org/10.1016/j.bbagen.2004.03.002

12. S. Kapiotis, M. Hermann, M. Exner, H. Laggner, B.M.K. Gmeiner, Copper- and magnesium protoporphyrin complexes inhibit oxidative modification of LDL induced by hemin, transition metal ions and tyrosyl radicals, Free Radic. Res. 39 (2005) 1193-1202.

http://dx.doi.org/10.1080/10715760500138981

13. J.P. Kamat, K.K. Boloor, T.P.A. Devasagayam, Chlorophyllin as an effective antioxidant against membrane damage in vitro and ex vivo, Biochim. Biophys. Acta, 1487 (2000) 113-127. http://dx.doi.org/10.1016/S1388-1981(00)00088-3

14. L. Ma, D. Dolphin, The metabolites of dietary chlorophylls, Phytochemistry, 50 (1999) 195-202.

http://dx.doi.org/10.1016/S0031-9422(98)00584-6

15. U.M. Lanfer-Marquez, R.M.C. Barros, P. Sinnecker, Antioxidant activity of chlorophylls and their derivatives, Food Res. Int. 38 (2005) 885-891. http://dx.doi.org/10.1016/j.foodres.2005.02.012

16. H.Y. Zhang, S.R. Jinga, J.Y. Zhu, H.B. Huang, Preparation of sodium copper chlorophyllin from lotus leaves and stability investigation, J. Neijiang Normal Univ. 25 (2010) 55-57 (in Chinese).

17. J.Y. Zeng, W.G. Wu, W.B. Kong, X.X. Liu, L. Zhao, Preparation and stability of red clover sodium zinc chlorophyllin, J. Northwest Normal Univ. 48 (2012) 82-88 (in Chinese).

18. X. Li, X. Wen, Y. Fang, J. Li, H. Wu, The preparation of chlorophyll iron salt, Food Ferment. Ind. 38 (2012) 77-81 (in Chinese).
19. X.J. Duan, W.W. Zhang, X.M. Li, B.G. Wang, Evaluation of antioxidant property of extract and fractions obtained from red alga Polysiphonia urceolata, Food Chem. 95 (2006) 37-43. http://dx.doi.org/10.1016/j.foodchem.2004.12.015

20. M. Oyaizu, Studies on products of browning reaction: Antioxidative activity of products of browning reaction prepared from glucosamine, Jpn. J. Nutr. 44 (1986) 307-315. http://dx.doi.org/10.5264/eiyogakuzashi.44.307

21. L. Barros, P. Baptista, I.C.F.R. Ferreira, Effect of Lactarius piperatus fruiting body maturity stage on antioxidant activity measured by several biochemical assays, Food Chem. Toxicol. 45 (2007) 1731-1737. http://dx.doi.org/10.1016/j.fct.2007.03.006

22. C. Beauchamp, I. Fridovich, Superoxide dismutase: Improved assays and an assay applicable to acrylamide gels, Anal. Biochem. 44 (1971) 276-287. http://dx.doi.org/10.1016/0003-2697(71)90370-8

23. M.G. Ferruzzi, S.J. Schwartz, Thermal degradation of commercial grade sodium copper chlorophyllin, J. Agric. Food Chem. 53 (2005) 7098-7102. http://dx.doi.org/10.1021/jf051010s

24. K. Shimada, K. Fujikawa, K. Yahara, T. Nakamura, Antioxidative properties of xanthan on the autoxidation of soybean oil in cyclodextrin emulsion, J. Agric. Food Chem. 40 (1992) 945-948. http://dx.doi.org/10.1021/jf00018a005

25. G.K. Jayaprakasha, R.P. Singh, K.K. Sakariah, Antioxidant activity of grape seed (Vitis vinifera) extracts on peroxidation models in vitro, Food Chem. 73 (2001) 285-290. http://dx.doi.org/10.1016/S0308-8146(00)00298-3

26. S.I. Liochev, I. Fridovich, Superoxide from glucose oxidase or from nitroblue tetrazolium, Arch. Biochem. Biophys. 318 (1995) 408-410. http://dx.doi.org/10.1006/abbi.1995.1247

27. Y. Endo, R. Usuki, T. Kaneda, Antioxidant effects of chlorophyll and pheophytin on the autooxidation of oils in the dark. I. Comparison of the inhibitory effects, J. Am. Oil Chem. Soc. 62 (1985) 1375-1378. http://dx.doi.org/10.1007/BF02545962

28. Y. Endo, R. Usuki, T. Kaneda, Antioxidant effects of chlorophyll and pheophytin on the autooxidation of oils in the dark. II. The mechanism of antioxidative action of chlorophyll, J. Am. Oil Chem. Soc. 62 (1985) 1387-1390. http://dx.doi.org/10.1007/BF02545965

29. J.C. Kephart, Chlorophyll derivatives - Their chemistry, commercial preparations and uses, Econ. Bot. 9 (1995) 3-38. http://dx.doi.org/10.1007/BF02984956

30. A.P. Odin, Antimutagenicity of the porphyrins and non-enzyme porphyrin containing proteins, Mutat. Res. 387 (1997) 55-68. http://dx.doi.org/10.1016/S1383-5742(97)00023-9 